\title{
ANALISIS SISTEM KONTROL KECEPATAN PUTAR MOTOR MENGGUNAKAN METODE PID PADA ALAT PENGADUK SIRUP MANGGA
}

\author{
Bambang Priyadi \\ Jurusan Teknik Eektro, Politeknik Negeri Malang \\ email: priyadi_bebeng@yahoo.co.id \\ (Artikel diterima: Oktober 2019, direvisi: September 2019, diterima untuk terbit: Januari 2020)
}

\begin{abstract}
Abstrak - Pengadukan sirup mangga adalah sebuah proses yang dilakukan untuk melakukan percampuran antara air, sari buah mangga dan gula pasir. Proses agitasi (pengadukan) merupakan faktor yang perlu diperhatikan dalam proses pembuatan sirup mangga. Pengadukan berfungsi untuk mencampur bahan pembuat sirup dan menjaga agar gula pasir tidak mengendap di bawah dan meratakan temperature pada tangki pengaduk sirup mangga. Oleh karena itu pemilihan jenis pengaduk dan kecepatan pengaduk yang tepat diharapkan dapat menunjang fungsi pengadukan sehingga dapat meningkatkan hasil kwalitas sirup mangga. Sistem pengontrol kecepatan putaran motor ini menjaga agar kecepatan putaran motor tetap stabil pada perubahan kondisi viskositas medium. Mikrokontroler yang digunakan Atmega 8535. Sensor yang mendeteksi kecepatan putaran motor rotary encoder. Kontrol yang digunakan pada sistem pengontrolan kecepatan motor menggunakan PID untuk menjaga kestabilan kecepatan putaran motor dc. Tujuan dari penelitian ini adalah kecepatan pengadukan yang efektif dan efisien, penyesuaian kecepatan pengadukan sirup mangga yang tepat dapat menjaga kondisi sirup lebih tahan lama. Pengontrol kecepatan putaran motor ini mampu mengatur putaran pengadukan yang stabil pada perubahan kondisi kekentalan sirup mangga dengan sistem control didalamnya, sehingga kecepatan pengadukan yang konstan dapat menyebabkan percampuran sari buah mangga, air dan gula menyebar secara cepat dan merata. Hasil dari skripsi ini diharapkan dapat menyelesaikan permasalahan - permasalahan yang ada
\end{abstract}

Kata kunci: agitasi (pengadukan),mikrokontroler, sirup mangga, PID.

\section{Pendahuluan}

\section{A. Latar belakang}

Sirup mangga merupakan salah satu olahan mangga yang dibuat dari sari mangga yang dimasak dengan kadar gula yang tinggi dan air sehingga diperoleh cairan yang kental. Pada saat proses pengadukan diperlukan tenaga yang lebih karena melewati beberapa proses yaitu proses melarutkan gula dengan sari mangga dan proses mengentalkan cairan sehingga menjadi sirup.

Pada saat ini masih dilakukan pengadukan secara manual yang membutuhkan tenaga manusia yang banyak dan relatif memerlukan waktu yang lama. Pengadukan secara manual hanya efektif digunakan untuk jumlah yang kecil, sedangkan untuk skala home industry yang lebih besar memerlukan tenaga yang lebih banyak untuk proses pengadukannya. Proses pengadukan harus dilakukan dengan cermat dan tepat agar pemanasan merata dan tidak terjadi pengendapan yang mengakibatkan gosong guna menghasilkan sirup dengan kualitas yang baik (Soetedjo dkk, 2009).

Berdasarkan permasalahan pada alat untuk proses pengadukan sirup mangga supaya dapat terkendali kecepatan putaran motor yang stabil dan otomatis, maka perlu untuk melakukan penelitian rangkaian kontrol metode PID, apabila digunakan sebagai alat kontrol Kecepatan Putar Motor DC pada Alat Pengaduk Sirup Mangga yang stabil dan otomatis. Dengan harapan agar diperoleh suatu hasil produktifitas yang relatif lebih tinggi, waktu produksi lebih cepat serta meningkatkan efisiensi.

\section{B. Rumusan masalah}

Bedasarkan latar belakang permasalahan di atas dapat diperoleh rumusan masalah diantaranya:

- Bagaimana memilih rangkaian yang tepat untuk pengontrolan kecepatan putar motor dalam proses pengadukan sirup mangga

- Bagaimana menentukan setpoint yang tepat agar kecepatan putar motor tetap stabil dalam pengadukan sirup mangga?

\section{Tujuan Penelitian}

Tujuan hasil analisis dan hasil penelitian sistem rangkaian kontrol dengan metode PID (Proportional Integral Derivative) adalah sebagai berikut:

- Agar dapat merancang dan membuat sistem pengaturan kecepatan motor pada proses pengadukan sirup mangga menggunakan metode PID (Proportional Integral Derivative).

- Agar dapat membuat dan merancang sebuah alat pada proses pengadukan pembuatan sirup mangga dengan kapasitas produksi skala rumah tangga (home industry).

\section{Manfaat Penelitian}

Manfaat yang diharapkan dari hasil analisis dalam penelitian sistim kontrol metode PID adalah :

- Dapat merancang dan membuat alat untuk mengontrol motor dc secara stabil. pada setpoint yang telah ditentukan dengan menggunakan metode PID (Proportional Integral dan Derivative) yang tepat.

- Dapat merancang dan membuat alat untuk mengontrol motor dc yang bisa disetting sesuai yang dikehendaki.

- Dengan menggunakan metode PID (Proportional Integral dan Derivative) diharapkan dapat dimanfaatkan 
dalam membantu proses produksi sirup mangga pada home industri.

\section{LANDASAN TEORI}

Pada bab ini membahas tentang peneletian yang telah dilakukan sebelumnya serta membahas teori yang dapat menunjang dalam penyelesaian penelitian. Proses pengadukan sirup mangga dibutuhkan sebuah pengontrolan kecepatan yang diatur dengan metode PID agar proses pengadukan mangga dapat menghasilkan kualitas sirup yang baik. Komponen yang dibutuhkan pada alat ini adalah ATmega sebagai controller, LCD, keypad, rotary encoder dan motor DC. Berikut merupakan penjelasan dari beberapa komponen dan teori penunjang dalam pembuatan alat pengaduk sirup mangga.

Sirup adalah bahan minuman dalam kondisi kental karena kadar gula yang tinggi. Pengaturan putar kecepatan motor pada pembuatan sirup mangga dapat mempermudah dalam proses pengadukan karena tidak memerlukan adanya tenaga manusia, lebih efisien dan efektif karena dapat menghindari terjadinya pengendapan serta meratakan suhu pada saat proses pemasakan.

Pada bab ini akan membahas mengenai penelitianpenelitian terdahulu dan landasan teori yang menjadi dasar dalam pelaksanaan skripsi ini. Berikut merupakan penelitian yang pernah dibuat mengenai pengaturan kecepatan motor pada proses pengadukan:

Dian Ayu W (2016). Judul penelitian ini adalah kontrol kecepatan putar motor pengaduk nira menggunakan metode PID pada alat pembuat gula merah tebu. Pengontrolan kecepatan pengadukan dengan aktuator motor DC menggunakan metode kontrol PID yang ditanamkan pada arduino. Terdapat tiga variabel kecepatan yang digunakan yaitu $100 \mathrm{rpm}, 110 \mathrm{rpm}$ dan $130 \mathrm{rpm}$ yang digunakan untuk membandingkan kecepatan yang dapat menghasilkan gula merah terbaik.

Arga Rifky (2014). Judul penelitian ini adalah sistem pengaturan kecepatan motor pada alat pengaduk adonan dodol menggunakan kontroler PID. Pada alat ini menggunakan metode hand tunning. Dalam pembuatannya menggunakan sensor optocoupler untuk mendeteksi kecepatan putar motor dan menggunakan motor DC.

Rendy Ardiansyah (2013). Judul penelitian ini adalah perancangan dan pembuatan alat pengaduk adonan dodol dengan kecepatan konstan dan torsi adaptif. Menggunakan rangkaian terkontrol penyearah gelombang penuh yang dikombinasikan dengan rotary encoder sensor kecepatan dapat digunakan untuk menghasilkan pergerakan motor dengan kecepatan yang konstan dan torsi motor yang adaptif. Motor DC magnet permanen digunakan untuk menggerakkan pengaduk. Arus dan torsi motor diatur melalui tegangan masukannya dengan pengaturan sudut penyalaan SCR pada rangkaian terkontrol gelombang penuh.

Rangga Elga (2012). Judul peneltian ini adalah perancangan alat pengaduk adonan bakery menggunakan motor DC $1 / 2$ HP dengan kontroler PID. Adonan bakery merupakan adonan berbentuk kalis, sehingga dalam pengolahannya membutuhkan nilai gaya dan torsi yang cukup besar. Dengan nilai kecepatan 130rpm dan 160rpm untuk membandingkan agar mendapatkan hasil yang baik. Nilai PWM dapat berubah-ubah secara otomatis bergantung dari nilai umpan balik yang dkiberikan oleh sensor kecepatan sehingga kcepatan putar motor dapat diajag konstan.
Pada pengontrol kecepatan putar motor DC proses pengadukan alat pembuat sirup mangga menggunakan metode PID (Proportional Integral Derivative) ini dan memakai sensor kecepatan yaitu rotary encoder. Pada bab ini akan menjelaskan mengenai metode pengontrolan kecepatan putar motor DC, sensor dan proses pembuatan sirup mangga.

\section{A. Kontrol Proportional Integral Derivative (PID)}

PID merupakan kontroler untuk menentukan presisi suatu sistem instrumentasi dengan karakteristik umpan balik/feed back pada sistem tersebut. Komponen PID terdiri dari 3 jenis, yaitu Proportional, Integratif dan Derivatif, dengan masing-masing memiliki kelebihan dan kekurangan. Ketiganya dapat dipakai berpasangan maupun sendiri-sendiri, tergantung kebutuhan dari pengontrolannya.(Raden, 2011)

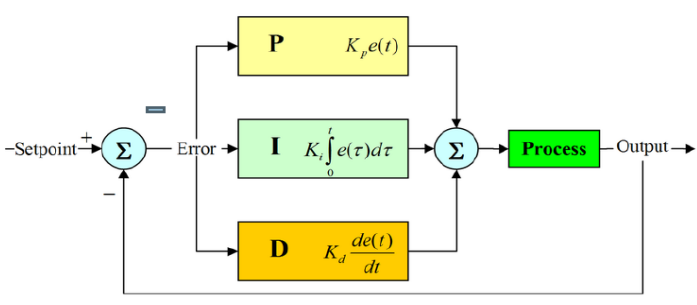

Gambar1 Blok Diagram PID Controller

Keluaran pengendali PID merupakan jumlahan dari keluaran pengendali proporsional, keluaran pengendali integral, dan keluaran pengendali diferensial. Sistem kontrol PID terdiri dari tiga buah cara pengaturan yaitu kontrol $\mathrm{P}$ (Proportional), D (Derivative) dan I (Integral), dengan masing-masing memiliki kelebihan dan kekurangan. Dalam implementasinya masing-masing cara dapat bekerja sendiri maupun gabungan diantaranya. Dalam perancangan sistem kontrol PID yang perlu dilakukan adalah mengatur parameter P, I atau D agar tanggapan sinyal keluaran sistem terhadap masukan tertentu sebagaimana yang diiginkan.

\section{B. Kerangka Pemikiran.}

Penelitian pada analisis adalah mengumpulkan studi literatur (mengumpulkan serta mempelajari yang berhubungan dengan penelitian yang akan dikerjakan yaitu Implementasi Metode PID Sebagai Pengontrol Kecepatan Putar Motor DC pada Alat Pengaduk Sirup Mangga), kemudian menganalisis dan merancang konsep serta spesifikasi pada alat pengaduk pembuatan sirup mangga. Setelah mengetahui bentuk mekanik, menentukan dan merancang rangkaian elektrik alat yang sesuai, selanjutnya melakukan pengujian apakah elektrik sesuai dengan bentuk mekanik yang ada. Langkah berikutnya adalah merancang software berupa metode PID dengan menghitung nilai parameter P, I dan D sesuai dengan teori yang ada untuk mengatur kecepatan putar motor pada alat pengaduk sirup mangga. Setelah itu melakukan pengujian parameter $\mathrm{P}$, I dan D terhadap respon system, supaya system dengan setpoint tertentu dengan tanpa beban bisa stabil. software dirancang berupa program agitasi otomatis. Apabila sistem berjalan sesuai dengan konsep rancangan yang dibuat, maka dilanjutkan dengan pengambilan data. Setelah tahapan pengambilan dan pengumpulan data dilakukan maka selanjutnya melakukan tahapan yang terakhir yaitu analisis data. 
Adapun lagkah-langkah yang dilakukan dalam tahap penelitian ini diantaranya adalah melakukan pengumpulan dan mempelajari semua literature yang berhubungan dengan kontrol PID dengan menggunakan metode Ziegler-nichols, dasar dasar dari kontrol kecepatan motor de dan literature pendukung lainnya yang berhubungn dengaan skripsi ini.

Studi literatur yang digunakan dalam penelitian ini untuk mencapai tujuan dari pembuatan alat.Tujuan dari penelitian ini adalah dengan mencari jurnal atau panduan ajar yang berhubungan dengan sistem kendali $P I D$ begitu juga dengan metode yang digunakan

\section{METODE}

\section{A. Tempat dan Waktu Penelitian}

Penelitian dilakuakan di kampus Politeknik Negeri Malang di dalam Laboratorium Teknik Elektronika. Penelitian dilakukan untuk mengetahui perilaku sensor terhadap hasil perencanaan dalam membuat sebuah alat yang kesemuanya dikontrol secara otomatis pada proses pembuatan sirup dengan bahan baku mangga. Penelitian dilakukan untuk mengamati besaran listrik input dan output hasil perencanaan antara lain adalah :

$\begin{array}{ll}\text { Tegangan Input } & : 220 \mathrm{VAC} \\ \text { Motor DC } & : \text { RPM } \\ \text { Sensor } & : \text { Rotary Encoder } \\ \text { DC Source } & : 19 \mathrm{~V} \\ \text { Display } & : \text { LCD } 16 \times 2\end{array}$

Untuk keperluan pengambilan data dan tampilan dalam penelitian ada dua perangkat yang diperlukan yaitu hardware dan software. Perancangan berupa diagram kerja sistem (hardware) dan algoritma tampilan dalam grafik pada layar monitor PC. Sedangkan perakitan berupa tahapan merangkai modul-modul rangkaian elektronik diperlukan sebagai alat pengambil data temperatur kerja tegangan dan arus.

\section{Pengujian dan Analisis}

\section{A. Pengujian Kontrol PID}

\section{Metode Ziegler- Nichols}

Pengujian dengan metode osilasi PID ZieglerNichols pada motor pengadukan dilakukan dengan memasukkan nilai $\mathrm{Kp}$ 0,205882 Ki dengan nilai 0,137255 dan Kd dengan nilai 0,077206 yang diperoleh melalui cara perhitungan pada bab 3. Analisis respon motor agitasi dari angka tersebut akan ditampilkan pada grafik hasil percobaan respon sistem osilasi PID Ziegler-Nichols akan ditunjukan pada Gambar 2

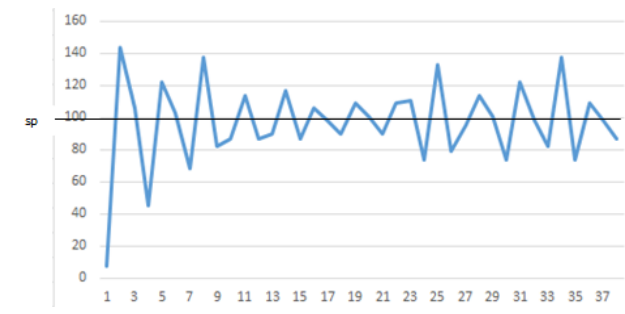

Gambar 2. Respon Sistem Motor Pengadukan Terkontrol Tanpa Beban

Gambar 2 menunjukan bahwa kecepatan motor pengadukan dengan kontrol tanpa beban memiliki maximum peak (Mp) yang lumayan tinggi yaitu $144 \mathrm{rpm}$ dengan percentage ofovershoot (Po)sangat tinggi yaitu $44 \%$ namun rising time -nya (Tr) sangat cepat yaitu 2 second. Dari setpoint yang ditentukan yaitu $100 \mathrm{rpm}$, sistem steady di kecepatan 106 rpm dengan settling time(Ts) 16 second dan mendapatkan error steady state (Ess) sebesar $6 \%$.

Tabel 1 Statistik PID tuning Ziegler-Nichols pada set-point $100 \mathrm{rpm}$

\begin{tabular}{|l|l|}
\hline Parameter & Hasil \\
\hline Time Rising (Tr) & $2 \mathrm{~s}$ \\
\hline Percentage of Overshoot (Po) & $44 \%$ \\
\hline Error Steady State (Ess) & $6 \%$ \\
\hline Settling Time (St) & $16 \mathrm{~s}$ \\
\hline
\end{tabular}

Respon sistem yang didapatkan dari tabel statistik di atas dengan menggunakan metode osilasi tuning Ziegler Nichols menghasilkan nilai yang jauh dari nilai set-point dan tidak stabil. Karena respon sistem yang tidak stabil maka hasil tuning dengan menggunakan metode Ziegler-Nichols kurang bagus jika diaplikasikan untuk sistem motor pengadukan, karena pada prinsipnya proses pengadukan

\section{Metode Trial and Errors}

Pengujian metode Trials and Error pada motor pengadukan dilakukan dengan memasukan nilai Kp, Ki dan Kd sampai kita mendapatkan respon sitem yang diinginkan. Nilai Kp yang di dapatkan adalah0,25, nilai Ki 0,15 dan $\mathrm{Kd}$ dengan nilai 0,0001 . Analisis respon motor pengadukan dari angka tersebut akan ditampilkan pada grafik hasil percobaan respon sistem osilasi Trials and Error akan ditunjukan pada graik 3

\section{B. Pengujian Tanpa Beban dengan Set Point 100 rpm}

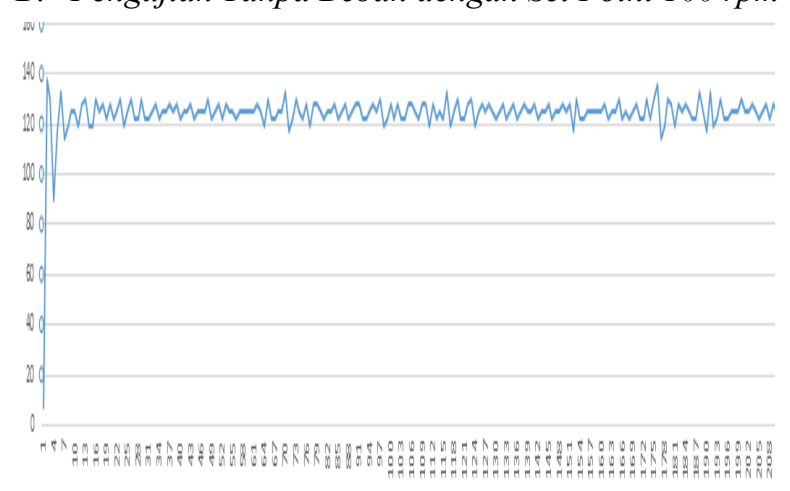

Gambar 3. Respon Sistem Motor Pengadukan Terkontrol Tanpa Beban dengan set point $100 \mathrm{rpm}$

Gambar grafik 3 diatas menunjukan bahwa kecepatan motor pengadukan dengan kontrol tanpa beban memiliki maximum peak (Mp) tidak terlalu tinggi yaitu $125 \mathrm{rpm}$ dengan percentage ofovershoot $(\mathrm{Po})$ tidak terlalu tinggi yaitu $25 \%$ danrising time - nya (Tr) yaitu 1,5 second. Dari setpointyang ditentukan yaitu $100 \mathrm{rpm}$, sistem steady di kecepatan $100 \mathrm{rpm}$ dengan settling time(Ts) 8 second dan mendapatkan error steady state (Ess) sebesar $0 \%$. 
Tabel 2 Statistik PID Tuning Trials and Error pada set-point $100 \mathrm{rpm}$

\begin{tabular}{|l|l|}
\hline Parameter & Hasil \\
\hline Time Rising (Tr) & $1,5 \mathrm{~s}$ \\
\hline Percentage of Overshoot (Po) & $25 \%$ \\
\hline Error Steady State (Ess) & $0 \%$ \\
\hline Settling Time (St) & $8 \mathrm{~s}$ \\
\hline
\end{tabular}

Respon sistem yang didapatkan dari tabel statistik di atas dengan menggunakan metode osilasi tuning Trials and Error di dapatkan nilai yang sesuai dengan nilai set-point dan stabil dengan Ess nya didapatkan nilai $0 \%$, systemdikatakan sesuai. Karena respon sistem yang stabil hasil tuning menggunakan metode Trials and Error dapat diaplikasikan untuk sistem motor pengadukan, karena pada prinsipnya prosesagitasi pengadukan membutuhkan kecepatan yang stabil pada nilai set-point yang ditetapkan.

\section{Pengujian Tanpa Beban dengan Set Point 125 rpm}

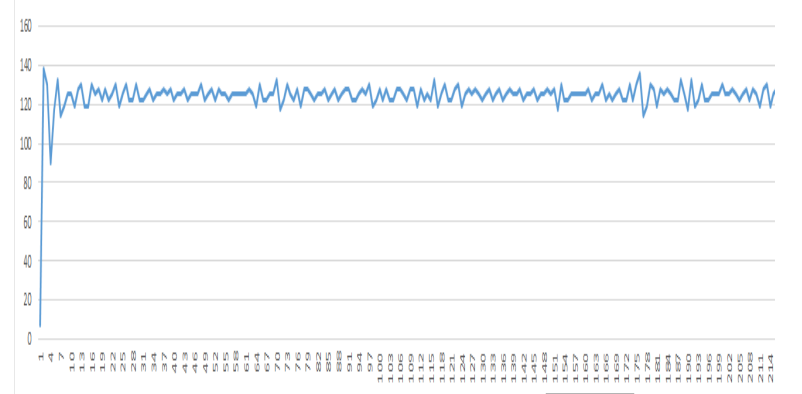

Gambar 4. Respon Sistem Motor Pengadukan Terkontrol tanpa Beban dengan Set-point $125 \mathrm{rpm}$

Gambar 4 diatas menunjukan bahwa kecepatan motor pengadukan dengan kontrol tanpa beban memiliki maximum peak (Mp) tidak terlalu tinggi yaitu $138 \mathrm{rpm}$ dengan percentage ofovershoot $(\mathrm{Po})$ tidak terlalu tinggi yaitu 10,4\% danrising time -nya ( $\mathrm{Tr}$ ) yaitu 1,5 second. Dari set-pointyang ditentukan yaitu $125 \mathrm{rpm}$, sistem steady di kecepatan 125,0047 rpm dengan settling time(Ts) 9 second dan mendapatkan error steady state (Ess) sebesar 0,003774 \%.

Tabel 3 Statistik PID Tuning Trials and Error pada Set-point $125 \mathrm{rpm}$

\begin{tabular}{|l|l|}
\hline Parameter & Hasil \\
\hline Time Rising (Tr) & $1,5 \mathrm{~s}$ \\
\hline Percentage of Overshoot (Po) & $10,4 \%$ \\
\hline Error Steady State (Ess) & $0,003774 \%$ \\
\hline Settling Time (St) & $9 \mathrm{~s}$ \\
\hline
\end{tabular}

Respon sistem yang didapatkan dari tabel statistik di atas dengan menggunakan metode osilasi tuning Trials and Error di dapatkan nilai yang sesuai dengan nilai set-point dan stabil dengan Ess nya didapatkan nilai 0,003774 \%, system masih dikatakan sesuai. Karena respon sistem yang stabil hasil tuning menggunakan metode Trials and Error dapat diaplikasikan untuk sistem motor pengadukan, karena pada prinsipnya proses agitasi pengadukan membutuhkan kecepatan yang stabil pada nilai set-point yang ditetapkan.
D. Pengujian Tanpa Beban dengan set point 150 rpm

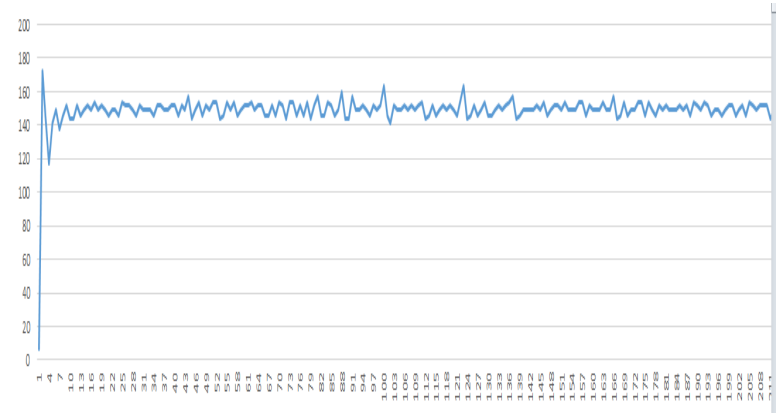

Gambar 5 Respon Sistem Motor Pengadukan Terkontrol tanpa Beban dengan set point $150 \mathrm{rpm}$

Gambar grafik 5 diatas menunjukan bahwa kecepatan motor pengadukan dengan kontrol tanpa beban memiliki maximum peak (Mp) tidak terlalu tinggi yaitu $172 \mathrm{rpm}$ dengan percentage ofovershoot $(\mathrm{Po})$ tidak terlalu tinggi yaitu $14,7 \%$ danrising time -nya ( $\mathrm{Tr}$ ) yaitu 1,5 second. Dari setpointyang ditentukan yaitu $150 \mathrm{rpm}$, sistem steady di kecepatan 150,0096 rpm dengan settling time(Ts) 9 second dan mendapatkan error steady state (Ess) sebesar 0,00638\%.

Tabel 4 Statistik PID Tuning Trials and Error pada Set-point 150 rpm

\begin{tabular}{|l|l|}
\hline Parameter & Hasil \\
\hline Time Rising (Tr) & $1,5 \mathrm{~s}$ \\
\hline Percentage of Overshoot (Po) & $14,7 \%$ \\
\hline Error Steady State (Ess) & $0,00638 \%$ \\
\hline Settling Time (St) & $9 \mathrm{~s}$ \\
\hline
\end{tabular}

Respon sistem yang didapatkan dari tabel statistik di atas dengan menggunakan metode osilasi tuning Trials and Error di dapatkan nilai yang sesuai dengan nilai set-point dan stabil dengan Ess nya didapatkan nilai 0,00638 \%, system masih dikatakan sesuai. Karena respon sistem yang stabil hasil tuning menggunakan metode Trials and Error dapat diaplikasikan untuk sistem motor pengadukan, karena pada prinsipnya proses agitasi pengadukan membutuhkan kecepatan yang stabil pada nilai set-point yang ditetapkan.

\section{E. Pengujian Sistem}

Pengujian sistem dengan Trials and Error dilakukan dengan menganalisa statistik dari respon sistem kecepatan motor pengadukan berdasarkan volume beban yang berbeda, sesuai dengan kontrol PID yang dilakukan. Pengujian sistem dilakukan dengan 2 variabel beban yang berbeda-beda yaitu $1 \mathrm{~L}$ dan $3 \mathrm{~L}$. Dalam setiap pengujian variabel beban dilakukan 3 kali dengan variable set-point kecepatan yaitu 100 rpm, 125 rpm dan $150 \mathrm{rpm}$.

\section{Beban $1 \mathrm{~L}, \mathrm{Kp}=\mathbf{0 . 2 5}, \mathrm{Ki}=\mathbf{0 . 1 5}$ dan $\mathrm{Kd}=0.0001 * 100$ rpm}

Dari grafik pengujian sistem diatas beban $1 \mathrm{~L}$ dengan kecepatan motor $100 \mathrm{rpm}$ dan diberi nilai Kp sebesar 0.25, Ki diberi nilai sebesar 0.15 dan $\mathrm{Kd}$ diberi nilai sebesar $0.0001 \mathrm{di}$ dapatkan time rising (Tr) yang lumayan cepat yaitu 2 second dengan percentage of overshoot (Po) $36 \%$. Sistem mulai menemui titik stabil pada waktu 21 second dengan error steady state (Ess) sebesar $1 \%$. Presentasi error sistem pada saat kondisi stabil akan ditampilkan pada hitungan ess di bawah : 


$$
\begin{aligned}
& \text { ess }=(\text {-steady state })+\text { Set Point } \\
&=-101+100
\end{aligned}
$$

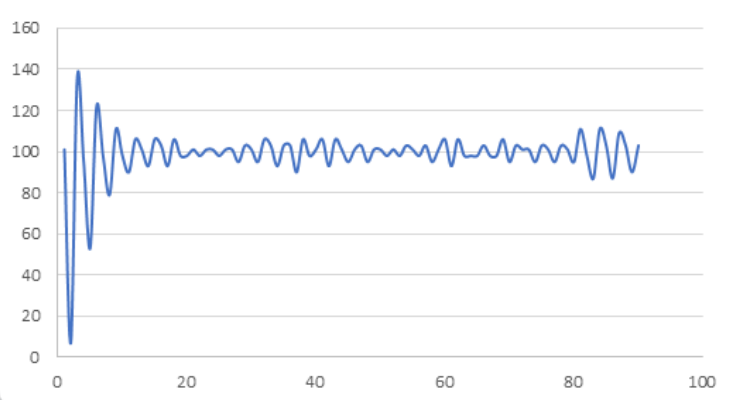

Gambar 6. Respon Sistem Motor Pengadukan 1 L \&100 rpm

Berdasarkan respon sistem diatas dengan kecepatan agitasi $100 \mathrm{rpm}$ pada beban $1 \mathrm{~L}$ waktu yang dibutuhkan sistem untuk mencapai titik kestabilan mencapai 20 second dimulai dengan adanya lonjakan kecepatan tertinggi pada waktu sistem dimulai yaitu $136 \mathrm{rpm}$ kemudian perlahan mencapai set-poinT $100 \mathrm{rpm}$ dengan error kestabilan atas 103 rpm dan error kestabilan bawah $97 \mathrm{rpm}$. Sistem memang tidak dapat konstan pada set-point yang ditetapkan namun masih dalam batas toleransi error yang ditetapkan yaitu 5\%.

\section{Beban $1 \mathrm{~L}, \mathrm{Kp}=0.25, \mathrm{Ki}=0.15$ dan $\mathrm{Kd}=0.0001,125$ rpm}

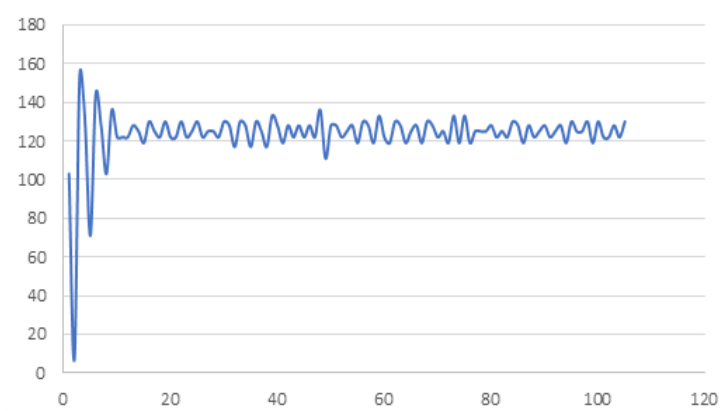

Gambar 7 Respon Sistem Pengadukan Sirup Beban 1 L \& 125 rpm

Dari grafik pengujian sistem menggunakan beban $3 \mathrm{~L}$ dengan kecepatan motor $125 \mathrm{rpm}$ dan diberi nilai Kp sebesar 0.25 , diberi nilai $\mathrm{Ki} 0.15$ dan $\mathrm{Kd}$ diberi nilai 0.0001 di dapatkan time rising ( $\mathrm{Tr}$ ) yang cukup cepat yaitu 1.8 second dengan percentage of overshoot (Po) 21,6 \%. Sistem mulai menemui titik stabil pada waktu 8 second dengan error steady state (Ess) sebesar $0.08 \%$. Presentasi error sistem pada saat kondisi stabil akan ditampilkan pada hitungan ess di bawah :

Berdasarkan respon sistem diatas dengan kecepatan agitasi $125 \mathrm{rpm}$ pada beban $3 \mathrm{~L}$ waktu yang dibutuhkan sistem untuk mencapai titik kestabilan mencapai 8 detik dimulai dengan adanya lonjakan kecepatan tertinggi pada waktu sistem dimulai yaitu $152 \mathrm{rpm}$ kemudian perlahan mencapai set-point $125 \mathrm{rpm}$ dengan error kestabilan atas $125.1 \mathrm{rpm}$ dan error kestabilan bawah $124.9 \mathrm{rpm}$. Sistem memang tidak dapat konstan pada set-point yang ditetapkan namun masih dalam batas toleransi error yang ditetapkan yaitu 5\% dari set-point.
Beban $3 \mathrm{~L}, \mathrm{Kp}=0.25, \mathrm{Ki}=0.15 \mathrm{dan} \mathrm{Kd}=0.0001 * 150 \mathrm{rpm}$

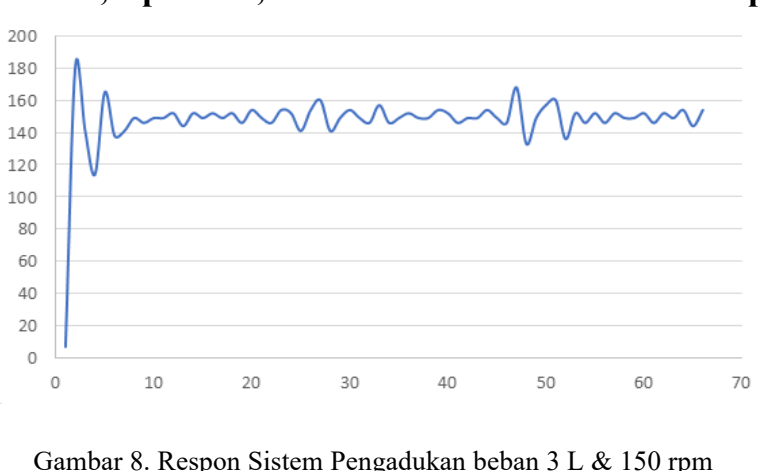

Dari grafik pengujian sistem menggunakan beban $3 \mathrm{~L}$ dengan kecepatan motor $150 \mathrm{rpm}$ dan diberi nilai Kp sebesar 0.25 , Ki diberi nilai sebesar 0.15 dan $\mathrm{Kd}$ diberi nilai sebesar 0.0001 di dapatkan time rising ( $\mathrm{Tr}$ ) yang lumayan cepat yaitu 1.8 second dengan percentage of overshoot $(\mathrm{Po}) 20.7 \%$. Sistem mulai menemui titik stabil pada waktu 8 second dengan error steady state (Ess) sebesar $1.8 \%$. Presentasi error sistem pada saat kondisi stabil akan ditampilkan pada hitungan ess di bawah :

ess $=\frac{\text { Steady state }- \text { Setpoint }}{\text { Setpoint }} \times 100 \%$

ess $=1.8 \%$

$$
=\frac{152,7-150}{150} \times 100 \%
$$

Berdasarkan respon sistem diatas dengan kecepatan agitasi $150 \mathrm{rpm}$ pada beban $3 \mathrm{~L}$ waktu yang dibutuhkan sistem untuk mencapai titik kestabilan mencapai 13 detik dimulai dengan adanya lonjakan kecepatan tertinggi pada waktu sistem dimulai yaitu $181 \mathrm{rpm}$ kemudian perlahan mencapai set-point $150 \mathrm{rpm}$ dengan error kestabilan atas $152.7 \mathrm{rpm}$ dan error kestabilan bawah $147.3 \mathrm{rpm}$. Sistem memang tidak dapat konstan pada set-point yang ditetapkan namun masih dalam batas toleransi error yang ditetapkan yaitu 5\% dari set-point.

Tabel 4.8 Statistik Respon Sistem pengadukan dengan beban 3 L pada kecepatan $100 \mathrm{rpm}, 125 \mathrm{rpm}$ dan $150 \mathrm{rpm}$

\begin{tabular}{|l|l|l|l|}
\hline \multirow{2}{*}{ Parameter } & \multicolumn{3}{|l|}{ Hasil pada RPM } \\
\cline { 2 - 4 } & 100 & 125 & 150 \\
\hline Time Rising (Tr) (s) & 1.5 & 1.8 & 1.8 \\
\hline $\begin{array}{l}\text { Percentage of } \\
\text { Overshoot (Po) (\%) }\end{array}$ & 38 & 21.6 & 20.7 \\
\hline $\begin{array}{l}\text { Error Steady State } \\
\text { (Ess) (\%) }\end{array}$ & 3.05 & 0.08 & 1.8 \\
\hline Settling Time (St) (s) & 14 & 8 & 8 \\
\hline
\end{tabular}

Pada Tabel 4.8 menunjukkan hasil pengujian pengadukan sirup dengan volume beban 3 liter sebanyak 3 kali yaitu menggunakan set-point $100 \mathrm{rpm}, 125 \mathrm{rpm}$ dan 150 rpm. Menurut referensi yang didapatkan, pengadukan harus dilakukan dengan kecepatan yang konstan dan stabil. Hasil pengujian menunjukkan bahwa variabel kecepatan yang sesuai kriteria pengadukan menggunakan kecepatan $125 \mathrm{rpm}$. Dapat dilihat dengan kecepatan $125 \mathrm{rpm}$ pada volume beban 3 liter memiliki rising time (Tr) yaitu 1.8 second juga tingkat 
kestabilan memiliki nilai error steady state yang sangat rendah yaitu mencapai $0.08 \%$ dan waktu yang dibutuhkan untuk mencapai pengadukan yang stabil adalah 14 second.

Dari analisa yang dilakukan dapat diketahui bahwa volume beban dapat menentukan variabel putaran yang sesuai dengan putaran yang konstan dan stabil pada range $100 \mathrm{rpm}$ - 150 rpm. Pada volume beban 3 liter variabel kecepatan yang sesuai dengan putaran yang konstan dan stabil berada pada kecepatan $125 \mathrm{rpm}$, Sedangkan pada volume beban 1 liter variabel kecepatan yang sesuai dengan putaran yang konstan dan stabil berada pada kecepatan $150 \mathrm{rpm}$, dimana dengan kecepatan 150 rpm stabil.

\section{KESIMPULAN DAN SARAN}

\section{A. Kesimpulan}

Dari hasil pengujian sistem keseluruhan dan pengujian hasil analisis yang telah dilakuaan maka dapat diambil kesimpulan sebagai berikut:

Dari hasil perancangan dan pengujian hardware yang telah dilakukan, hardware telah dibuat sesuai kebutuhan kecepatan putar motor. Mulai dari rangkaian driver motor dc, sensor kecepatan rotary encoder, lcd 16x2 dan lain-lain telah bekerja sesuai dengan apa yang dibutuhkan oleh sistem, dapat diambil kesimpulan bahwa alat pengaduk sirup mangga telah berhasil dibuat dan bekerja dengan baik, khususnya pada kecepatan putar motor yang dapat dikontrol kecepatannya.

Metode kontrol dilakukan tuning PID menggunakan Trials and Error dengan mengubah-ubah nilai dari $\mathrm{Kp}, \mathrm{Ki}$ dan $\mathrm{Kd}$ sampai didapatkan nilai $\mathrm{Kp}=0.25, \mathrm{Ki}=0.15$ dan $\mathrm{Kd}$ $=0.0001$. Setelah dilakukan pengujian respon sistem dengan set-point $100 \mathrm{rpm}$ diperoleh nilai error steady state yang cukup bagus yaitu $0 \%$. Jadi metode tuning PID trials and error sesuai untuk di implementasikan pada alat pengaduk sirup.

Volume beban dapat menentukan variable putaran yang sesuai dengan putaran yang konstan dan stabil. Pada volume beban 3 liter variable kecepatan yang sesuai dengan putaran yang konstan dan stabil berada pada kecepatan $125 \mathrm{rpm}$, sedangkan volume beban 1 liter variable kecepatan yang sesuai dengan putaran yang konstan dan stabil berada pada kecepatan $150 \mathrm{rpm}$

\section{B. Saran.}

Alat pengaduk sirup yang telah dibuat masih banyak kekurangan. Perlu adanya perbaikan dan penyempurnaan agar alat ini dapat bekerja secara optimal. Ada beberapa hal yang disarankan untuk perbaikan dan penyempurnaan yaitu :

- Dari segi mekanik, pada bagian atas masih belum di sediakan penutup untuk mencegah sirup tumpah saat di lakukan pengadukan.

- 2. Dari segi elektrik, perlu ditambahkan real-time clock (RTC) untuk memberikan penjadwalan proses pengadukan dan menjadwal waktu istirahat motor demi menjaga realibilitas motor dan juga lebih memperhatikan estetika pengkabelan pada box elektrik maupun kabel yang tersambung pada motor dan rangkaian elektrik pada box

\section{Daftar Pustaka}

[1] Andrianto, Moh. 2014. Kendali Kecepata Motor Direct Current (DC) Menggunakan Proportional Integral Derivative (PID)
Controller Terhadap Beban. Skripsi Teknik Elektro Politeknik Negeri Malang.

[2] Ardiansyah, dkk.2013. Rancang-Bagun Sistem Pengaduk Adonan Dodol Dengan Kecepatan Konstan dan Torsi Adaptif. Jurnal EECCIS. Universitas Brawijaya Balai Informasi LIPI. 2009. Nanas

[3] Fratama, Riza Ade. 2016. Implementasi Kontrol PI untung Pengaturan Kecepatan Motor DC Alat Pengupas Kulit Ari Kedelai. Skipsi Teknik Elektro Politeknik Negeri Malang.

[4] Hartati, M.E. 2010. Pengaruh Penggunaan Madu pada pembuatan Selai Pepaya. Jurnal Volume XLV, No.3, November 2010, pp29-37Berita Litbang Industri

[5] Nizar, Luthfi Fakhrudin. 2014. Sistem Pengendali Kecepatan Motor DC Pada Lift Barang Menggunakan Kontroller PID Berbasis ATMEGA 2560. Skripsi Teknik Elektro Universitas Brawijaya Malang.

[6] Nugraha,Arga Rifky. 2014. Sistem Pengaturan Kecepatan Motor DC pada Alat Pengaduk Adonan Dodol Menggunakan Kontroler PID. Jurnal Mahasiswa TEUB Vol 1, No 2. Universitas Brawijaya.

[7] Pradana, Ferdian. 2014. Perancangan Dan Implementasi Visual Servoing Pada Robot Beroda Menggunakan Kamera Berbasis Beaglebone Black. Skripsi Teknik Elektro Politeknik Negeri Malang

[8] Santoso, Feri. 2012. Produksi Pembuatan Selai Sawo Kaya Akan Vitamin C. Laporan Tugas Akhir Teknologi Hasil Pertanian Universitas Sebelas Maret

[9] Syahrumsyah, Hudaida, dkk. 2010. Widianti, Dian Ayu. 2016. Kontrol Kecepatan Putar Motor Pengaduk Nira Menggunakan Motode PID Pada Alat Pembuat Gula Merah Tebu. Skipsi Teknik Elektro Politeknik Negeri Malang.

[10] Malvino, Albert Paul. 1987. Prinsip-prinsip Elektronika, Terjemahan Irwan Wijaya. Jakarta: Erlangga.

[11] Motorola Semiconductor. www.google.com. dicuplik pada tanggal 6 Maret 2007.

[12] Pernantin Tarigan, 2001, "Rangkaian Logika", edisi kedua, USU Press, Medan. 